\title{
Extractivismo:
}

\section{una discusión interamericana}

\section{HENRY VELTMEYER*}

La expansión del capital extractivo en la era neoliberal del desarrollo capitalista entraña grandes desafíos para los Estados y sobre todo las comunidades afectadas que se materializan en intensos debates políticos y académicos que cobran especial significado en la discusión interamericana. La preocupación central del texto es la economía política de la extracción de recursos naturales, con énfasis en las contradicciones y las implicaciones para el desarrollo de la estrategia de desarrollo económico adoptada por un número creciente de países en América - particularmente en el cono sur de América del Sur y los Andesy por Canadá en América del Norte. Detrás de esta preocupación, que es esencialmente intelectual o teórica, subyace la preocupación más práctica y existencial de las comunidades indígenas y no indígenas que se ven afectadas negativamente por las operaciones del capital extractivo.

\section{Introducción}

Los modelos de desarrollo económico basados en la extracción de recursos naturales (extractivismo) han sido objeto de controversia y fuente de conflicto entre Estados, corporaciones transnacionales, comunidades y movimientos obreros desde las primeras décadas del siglo XX, incluso antes. De hecho, podría

* Docente investigador, Unidad Académica de Estudios del Desarrollo,

Universidad Autónoma de Zacatecas. Traducción del inglés al español por Humberto Márquez argumentarse ${ }^{1}$ que el extractivismo fue una forma de capitalismo que precedió al capitalismo industrial, un sistema basado en la explotación del trabajo (el «suministro ilimitado de excedentes de mano de obra rural o agríco-

${ }^{1}$ Norman Girvan, «Extractive imperialism in historical perspective: a caribbean view», Ponencia en la conferencia Alternative Trade and Development, Saint Mary's University, Halifax, noviembre 2013. la»), por varios siglos. Desde esta perspectiva - definiendo el capitalismo sobre la base de la relación capital-trabajo - el capitalismo, tal como lo conocemos, es decir, como un sistema utilizado para expandir las fuerzas productivas de la sociedad y lograr mejoras notables en la condición social de la población mundial, ha tenido una historia relativamente corta que se remonta al siglo XIX cuando se construyeron los pilares fundamentales del sistema.

En ese sentido, lo que ahora se entiende como «neoextractivismo» (la combinación del extractivismo con una nueva política social diseñada para lograr una forma de desarrollo más inclusiva) es el resultado de las condiciones generadas en la década de 1980 dentro del marco institucional y político de un «nuevo orden mundial» (capitalismo de libre mercado, 

primarios. Esta estrategia no era nueva para América Latina: era objeto de la crítica lanzada desde la «teoría de la dependencia», una teoría que atribuía la falta de desarrollo o el subdesarrollo de los países de la región a una estructura económica en la que los países de la periferia exportaban materias primas y productos primarios a cambio de la importación de bienes fabricados en el centro del sistema. Respecto a esa teoría, varios países de la región iniciaron una política de industrialización por sustitución de importaciones basada en la regulación del capital y la protección de las empresas y productores nacionales. Sin embargo, la instalación de un «nuevo orden mundial» centrado en un programa de «reformas estructurales» (globalización neoliberal) en los 1980 creó una contra-dinámica que dio lugar a una profundización de esta relación de dependencia mediante la afluencia de capitales que «buscan recursos» y una correspondiente reprimarización de las exportaciones.

El cuadro 1 presenta una descripción gráfica de dicho proceso, mismo que podría ser considerado como una nueva geoeconomía del capital fundamentado en la expansión del capital extractivo en la región. Asimismo, ofrece un vistazo a la geoeconomía de los flujos de capital - el predominio del capital buscador de recursos y un flujo creciente hacia la periferia sudamericana, donde una variedad de condiciones conspiraban para crear condiciones favorables al resurgimiento del capital extractivo-, incluyendo un auge de materias primas y gobiernos complacientes ansiosos de aprovechar su ven- taja comparativa en recursos naturales. Varios cambios en la economía global, especialmente el ascenso de China como potencia económica y la expansión de la demanda de recursos naturales, ayudaron y fomentaron ese proceso, lo que derivó en la «nueva dependencia». ${ }^{4}$

Dentro del contexto latinoamericano, esta nueva dependencia se ha traducido en la explotación de los recursos naturales y la exportación de bienes primarios (hidrocarburos, metales, minerales, productos agroalimentarios, recursos forestales y biocombustibles) en gran escala. ${ }^{5}$ Los proyectos extractivos suelen implicar inversiones a gran escala, a menudo extranjeras, en la adquisición de tierras - denominadas landgrabbing en el discurso de estudios agrarios críticos - ${ }^{6}$ concesiones para exploración y extracción de metales y minerales, proyectos de desarrollo de infraestructura emprendidos por empresas transnacionales y actividades intensivas en capital que generan poco empleo más allá de la fase de construcción. De igual manera,

\footnotetext{
${ }^{4}$ Atilio Borón, «Teorías de la dependencia», Realidad Económica, núm. 238, agosto-septiembre 2008; Adrián Sotelo, «Neoimperialismo, dependencia e novas periferias», en $A$ América Latina e os desafíos da globalizaca, Rio de Janeiro, Boitempo, 2009; Carlos Eduardo Martins, Globalizacao, dependencia e neoliberalismo na América Latina, Sao Paulo, Boitempo, 2011.

${ }^{5}$ Maristella Svampa, «Resource extractivism and alternatives: Latin American perspectives on development», Journal für Entwicklungspolitik, vol. 28, núm. 3, 2012, pp. 43-73; Maristella Svampa y Enrique Viale, Maldesarrollo. La Argentina del extractivismo y el despojo, Buenos Aires, Katz, 2014. ${ }^{6}$ Saturnino Borras, Jennifer Franco, Sergio Gomez, Cristobal Kay \& Max Spoor, «Land grabbing in Latin America and the Caribbean», Journal of Peasant Studies, vol. 39, núms. 3-4, 2012, pp. 845-872.
}

Cuadro 1. Distribución porcentual de IED por sector en América Latina

\begin{tabular}{lccccccccc} 
& 2000 & 2001 & 2002 & 2003 & 2004 & 2005 & 2006 & 2007 & 2008 \\
\hline Recursos & 10 & 12 & 12 & 11 & 12 & 13 & 12 & 15 & 30 \\
Manufactura & 25 & 26 & 38 & 35 & 38 & 37 & 36 & 35 & 22 \\
Servicios & 60 & 61 & 51 & 48 & 46 & 48 & 51 & 49 & 47 \\
\hline
\end{tabular}

Fuente: adaptado de Juan Martín Arellano, «Canadian foreign direct investment in Latin America», Background Paper, North-South Institute, Ottawa, 2010 (tabla 2), basado en datos de CEPAL. 
el extractivismo requiere una constante expansión territorial (la extensión de la frontera extractiva en áreas remotas donde aún quedan grandes reservas inexplotadas de minerales, fuentes de energía y productos agroalimentarios) que conduce al desplazamiento o la destrucción de alternativas, formas locales de producción y modos de vida. El resultado, para Svampa y otros estudiosos latinoamericanos del extractivismo, ${ }^{7}$ es la proliferación de economías de enclave y la fragmentación de territorios indígenas y campesinos mediante el despojo: «acumulación por desposesión» en el discurso marxista. ${ }^{8}$

En el nuevo milenio, las condiciones cambiantes produjeron una dinámica totalmente diferente apoyada en la reciente geopolítica y geoeconomía del capital extractivo. A nivel político, el activismo de los movimientos sociales campesinos en la década de 1990 en re-

\footnotetext{
${ }^{7}$ Eduardo Gudynas, «The new extractivism in South America: ten urgent theses about extractivism in relation to current South American progressivism», Bank Information Center, 2010, en http://www.bicusa.org/en/Article.11769.aspx; «La izquierda de los límites al nuevo extractivismo», La Primera Digital, 11 de mayo de 2011, en http://www.diariola primeraperu.com/online/columnistas/la-izquierda-de-loslimites-al-nuevo-extractivismo_85841.html; «Extractivisms: concepts...»

${ }^{8}$ David Harvey, The new imperialism, Oxford, Oxford University Press, 2003.
}

sistencia contra la agenda política neoliberal generó un desencanto y el rechazo del neoliberalismo como doctrina económica y modelo de desarrollo. Al final de la década, el neoliberalismo estaba a la defensiva y dio paso a una sucesión de regímenes «progresistas» (anti o posneoliberales) orientados hacia lo que se ha descrito como «activismo estatal inclusivo» (el uso de rentas de recursos recolectadas en el proceso de exportación de productos básicos para financiar programas de reducción de la pobreza). Este desarrollo se reflejó en el discurso teórico en torno a la discusión sobre el «neoextractivismo». ${ }^{9}$

Bajo las condiciones del auge de las materias primas en el mercado mundial y el rechazo generalizado del neoliberalismo en los círculos políticos y el sector popular, así como el giro de varios gobiernos hacia el activismo estatal incluyente, lejos del neoliberalismo, el extractivismo, junto con la reprimarización de las exportaciones, se convirtió en la forma dominante de acumulación de capital y de desarrollo nacional en la región.

9 Eduardo Gudynas, «The new extractivism...»; Henry Veltmeyer y James Petras (eds.), The new extractivism, London, Zed Books, 2014, pp. 54-55.
El extractivismo también requiere una constante expansión territorial que conduce al desplazamiento o la destrucción de alternativas, formas locales de producción y modos de vida. 
El desarrollo más importante del «agroextractivismo» es la conversión de la tierra para la producción de alimentos a la producción de biocombustibles como la soya.

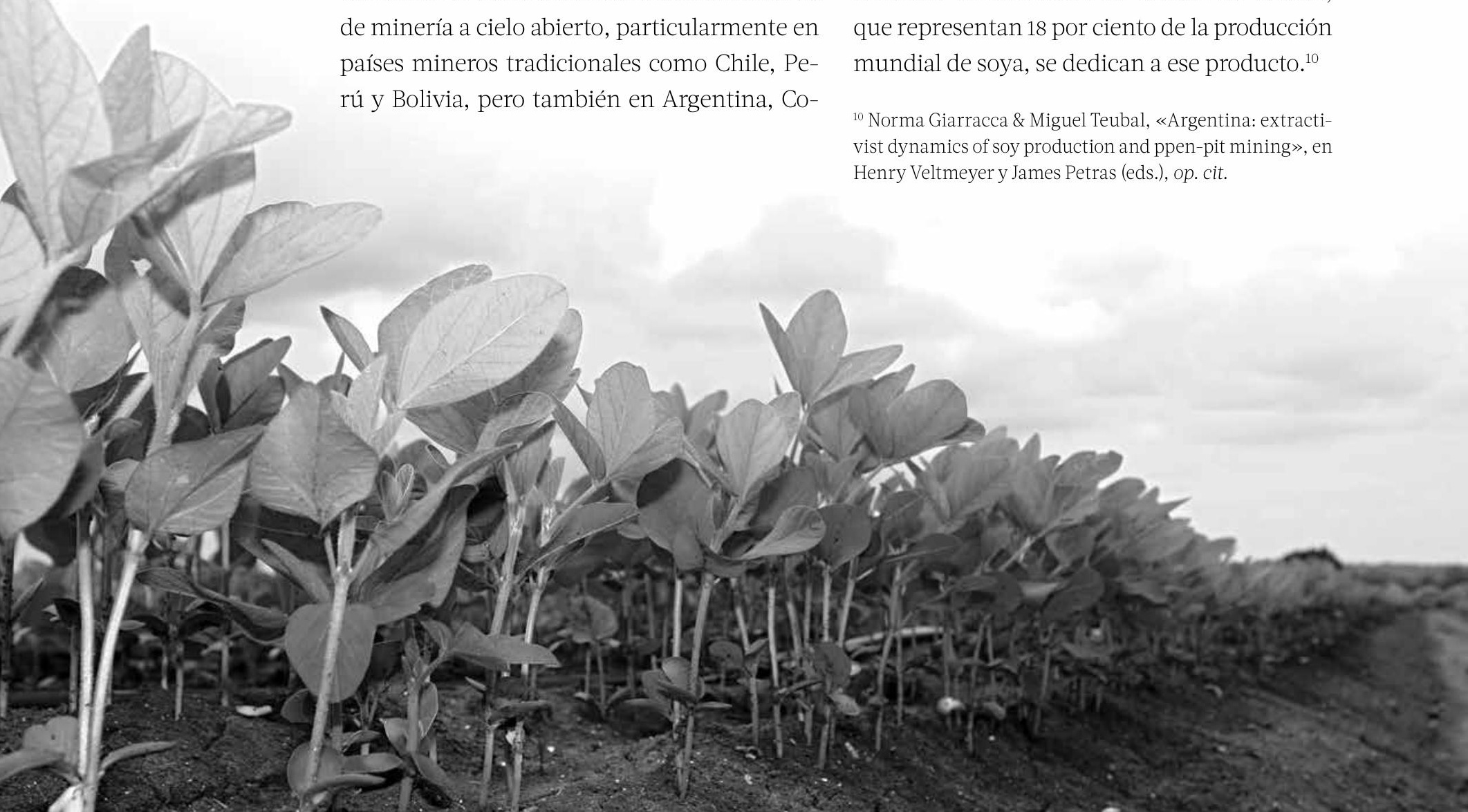

lombia, México y Brasil, el mayor receptor de inversiones directas extranjeras que buscan recursos.

Un tercer sector podría denominarse «agroextractivismo»: la extracción de productos agroalimentarios y forestales (actividad que también se remonta siglos atrás, pero que ha adquirido una relevancia creciente en los últimos años en el comercio mundial de productos básicos). El desarrollo más sobresaliente en este sector es la conversión de la tierra para la producción de alimentos a la producción de energía en forma de biocombustibles como el etanol y la soya.

Los biocombustibles como fuente de energía se han convertido en una de las principales fuerzas impulsoras del desarrollo capitalista en América del Sur. En el caso de Paraguay y Uruguay, más de 60 por ciento de las tierras arables del país se dedican ahora a la producción de soya para la exportación. En Bolivia, la soya es el cultivo más preciado en el sector agrícola, con más de 14 mil productores y 45 mil trabajadores, más que los dedicados a la producción de coca, el cultivo tradicional de agroextracción. Por su parte, en Argentina, más de 19.5 millones de hectáreas de tierras de cultivo, que representan 18 por ciento de la producción mundial de soya, se dedican a ese producto. ${ }^{10}$

${ }^{10}$ Norma Giarracca \& Miguel Teubal, «Argentina: extractivist dynamics of soy production and ppen-pit mining», en Henry Veltmeyer y James Petras (eds.), op. cit. 
Previsiblemente, dicha dinámica ha dado lugar a nuevos ciclos y modos de resistencia y repertorios de protesta social, así como a los importantes conflictos sociales sobre los derechos territoriales a la tierra, el agua y los recursos naturales. ${ }^{11}$ Mientras que el modelo extractivo ha asumido formas más violentas en los países gobernados por fuerzas de la derecha (más infame en Colombia, donde los proyectos mineros han avanzado bajo el escudo protector de paramilitares escuadrones de la muerte), pero también en Guatemala, los regímenes de centro-izquierda dentro de lo que se entiende como un «ciclo progresista» en la política latinoamericana ${ }^{12}$ también lo han abrazado y han mediado enfrentamientos entre el capital extractivo y los movimientos socioambientales en el sector popular. Los territorios y comunidades indígenas están a la vanguardia tanto de la frontera extractiva como de los conflictos sociales relacionados.

Tales conflictos, y las presiones y luchas asociadas, suelen oponer a los movimientos campesinos e indígenas contra las empresas del sector extractivo y a veces los gobiernos que facilitan sus operaciones. ${ }^{13}$ En esta situación, las comunidades indígenas y campesinas en las zonas donde se encuentran los recursos buscados y donde se extraen se enfrentan a fuerzas y condiciones que conducen a la desposesión de sus tierras, la pérdida de sus medios de subsistencia, el pillaje y el saqueo de los recursos del subsuelo, la degradación del medio ambiente y de su hábitat, de igual manera la privatización, la mercantilización y la contaminación del agua de la que dependen sus medios de subsistencia, salud y bienestar, por no decir la vida misma. Paralelamente, mientras que las empresas mineras están obte-

\footnotetext{
${ }^{11}$ Anthony Bebbington y Jeffrey Bury (eds.), Subterranean struggles: new dynamics of mining, oil and gas in Latin America, Austin, University of Texas Press, 2013.

${ }^{12}$ Véase James Petras y Henry Veltmeyer, What's left in Latin America, Ashgate Publishing, 2009.

${ }^{13}$ Anthony Bebbington y Jeffrey Bury (eds.), op. cit.
}

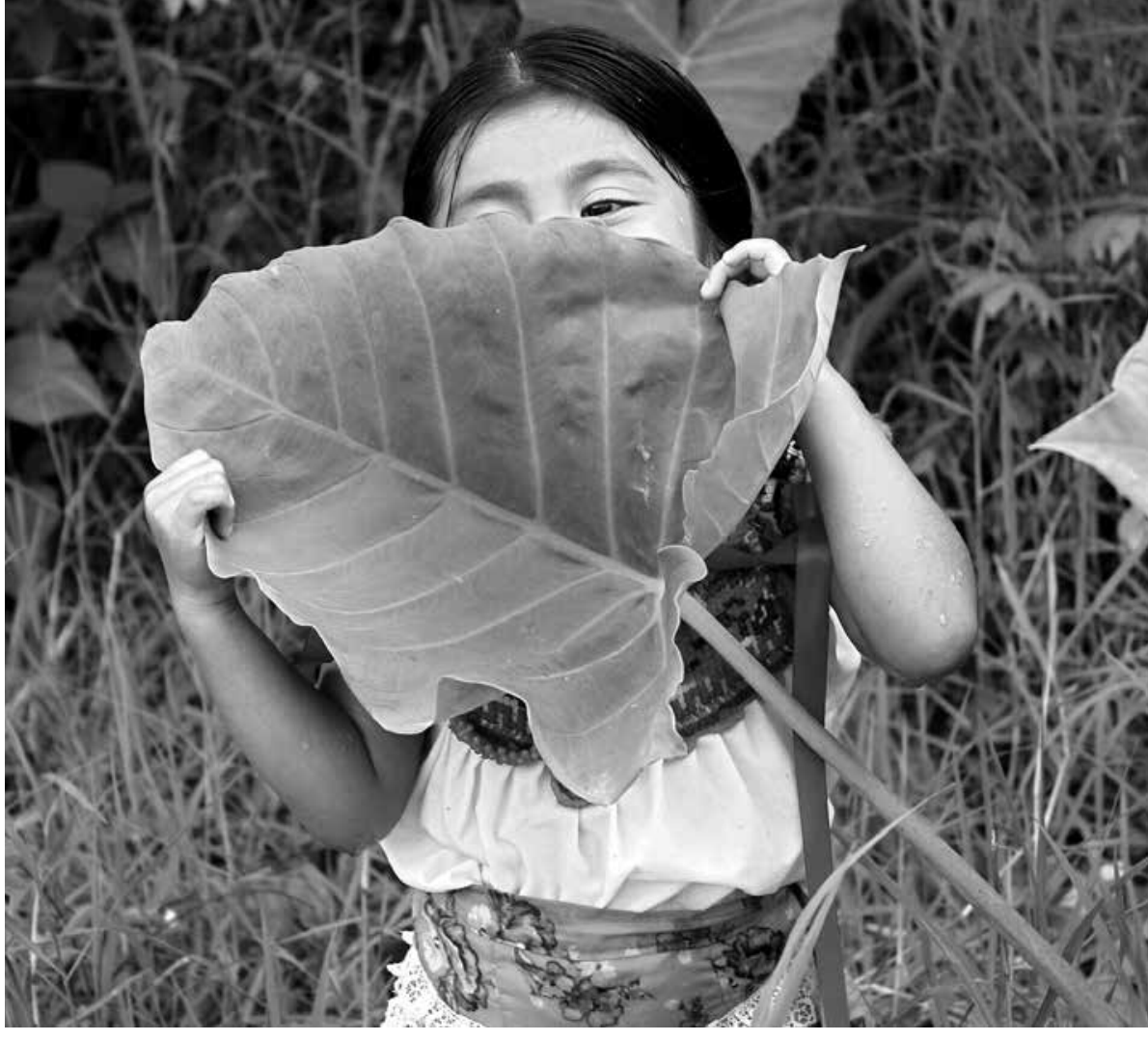

niendo ganancias inesperadas a medida que se suben a la ola del alza de precios asociada con el auge de los productos primarios, los gobiernos han llegado a depender cada vez más de la inversión extranjera directa para la extracción de recursos naturales de sus países como de los ingresos derivados de las rentas de los recursos recaudados en el proceso.

\section{Escuelas de pensamiento sobre el extractivismo}

En los debates que han rodeado la cuestión del «extractivismo» han surgido tres escuelas de pensamiento. La primera incluye a los defensores del «crecimiento inclusivo» o desarrollo sustentable de los recursos naturales y aquellos que favorecen y apoyan el extractivismo como una estrategia de desarrollo económico, pero lo ven como un tema de desarrollo socialmente responsable o como un tema de gestión (gestión de recursos y gestión de los inevitables conflictos que genera el capitalismo extractivo).

Una segunda escuela de pensamiento podría ser etiquetada como «antiextractivista»,
Las comunidades indígenas y campesinas que se encuentran en las zonas de los recursos buscados se enfrentan a la desposesión de tierras, la pérdida de medios de subsistencia y la degradación del hábitat, así como la privatización, mercantilización y contaminación del agua de la que dependen los medios de subsistencia, la salud y el bienestar. 
ya sea porque el extractivismo es visto como fundamentalmente incompatible con los valores culturales que las comunidades indígenas y los ecologistas ponen en el medio ambiente y con la protección de sus derechos territoriales y medios de subsistencia, o por las profundas contradicciones del capital extractivo con el desarrollo o posdesarrollo en la forma de vivir bien en solidaridad social y en armonía con la naturaleza. ${ }^{14}$ Esta escuela antiextrativista reúne a ecologistas y ecologistas sociales que priorizan el medio ambiente por encima del industrialismo y el extractivismo en cualquiera de sus formas (independientemente de la responsabilidad social y ambiental de las empresas o de pretensiones de «sustentabilidad» o inclusión social), así como los economistas políticos marxistas preocupados por las contradicciones del capital extractivo e incluso por los economistas del desarrollo preocupados por las implicaciones del desarrollo en lo que se ha denominado como la «maldición de los recursos»..$^{15}$

Hay una tercera escuela de pensamiento, mucho más pequeña, en la que destaca Alvaro García Linera, vicepresidente de Bolivia. Él es el principal ideólogo del «socialismo» en el contexto boliviano, aquí socialismo no es visto como un sistema alternativo al capitalismo o «un nuevo modo de producción que coexistiría junto al capitalismo» sino como «campo de batalla entre el capitalismo en crisis y las tendencias, las potencialidades y los esfuerzos para llevar la producción bajo la propiedad y el control de la comunidad». ${ }^{16}$ Es un sociólogo muy connotado

\footnotetext{
${ }^{14}$ Fernando Huanacuni Mamani, Buen Vivir/Vivir Bien: filosofía, politicas, estrategias y experiencias regionales andinas, Lima, Coordinadora Andina de Organizaciones Indígenas, 2010.

${ }^{15}$ Alberto Acosta, La maldición de la abundancia, Quito, Comité Ecuménico de Proyectos/AbyaYala, 2009; Stephen Haber y Victor Menaldo, «Natural resources in Latin America: neither curse nor blessing», SSRN Working Paper, Oxford Handbook of Latin American Political Economy, 2012, en http://ssrn. com/abstract=1625504

${ }^{16}$ Álvaro García Linera, «Once again on so-called extractivism», Monthly Review, abril 2013, p. 4.
}

convencido de que es posible combinar el extractivismo con el socialismo y el concepto indígena de «Vivir Bien» (Buen Vivir en Ecuador o Vivir Bien en Bolivia). ${ }^{17}$

Una conclusión similar es alcanzada por la socióloga argentina Maristella Svampa sobre la base de un examen de los estudios ecológico-políticos de pensadores como Alberto Acosta y Eduardo Gudynas, y un enfoque particular en sus propuestas para una transición del capitalismo extractivo hacia un posdesarrollo futuro alternativo. Ella asevera que esto no significa que se detendrá a todas las actividades extractivas, sino que se dará prioridad a la elevación de los niveles de vida en un marco de producción verdaderamente sustentable o, como argumentó García Linera, «aumentar la propiedad y el control comunales» sobre los procesos productivos, extractivistas o no extractivistas, y asegurar la «distribución social de la riqueza resultante», «para generar riqueza [vía extracción de recursos naturales] y redistribuirla entre la población, reduciendo la pobreza y la extrema pobreza»..$^{18}$

En tal concepción, la extracción de recursos naturales se orientaría principalmente hacia las necesidades endógenas en lugar de oportunidades de mercado impulsadas por el exterior y se mantendría dentro de límites ecológicos estrictos. Las medidas inmediatas que se tomarían incluirían impuestos extraordinarios y la redistribución de los vastos beneficios obtenidos por las empresas mineras, así como una moratoria en la exploración de nuevos yacimientos de petróleo y gas. El éxito de cualquier transición dependería del equilibrio regional de las fuerzas sociales y de las medidas adoptadas a escala mundial para poner fin al uso de combustibles fósiles.

\footnotetext{
${ }^{17}$ Eduardo Gudynas y Alberto Acosta, «El Buen Vivir más allá del desarrollo», Revista Qué Hacer, núm. 181, 2011, pp. 70-81. ${ }^{18}$ Álvaro García Linera, op. cit., p. 7.
} 
La guerra por el agua: la nueva frontera de la resistencia al extractivismo

El acceso de los pobres del mundo al agua potable ha sido uno de los problemas fundamentales a los que se ha enfrentado la comunidad del desarrollo durante muchas décadas, problema que se ha acentuado en los últimos años por la extensión de la agenda neoliberal a la privatización de los medios de producción social y la mercantilización de los recursos productivos de la tierra y los bosques, el agua y las vías navegables, los minerales y metales del subsuelo. A lo largo del siglo xx, el desarrollo capitalista de las fuerzas productivas se asoció con un proceso de «acumulación por desposesión» — desposesión del pequeño productor rural, los agricultores familiares o campesinos con tierras, hecho que desembocó en una lucha por la tierra que se ha prolongado durante un siglo. Sin embargo, el giro o regreso del capitalismo en los últimos años hacia una estrategia extractiva (versus una estrategia basada en la explotación de un suministro ilimitado de excedentes de mano de obra agrícola) ha desplazado la lucha de clases y las fuerzas de resistencia lejos de la tierra y hacia la resistencia de los nuevos recintos de los bienes comunes globales, es decir, para resistir las fuerzas del desarrollo capitalista que se han movilizado para privatizar y mercantilizar el último elemento restante de los bienes comunes mundiales: el agua. ${ }^{19}$

Un hito sobresaliente y un punto de inflexión de este «desarrollo» fue la guerra del agua en Cochabamba, Bolivia, una serie de protestas que tuvo lugar en la tercera ciudad más grande de Bolivia entre diciembre de 1999 y abril de 2000 en respuesta a la privatización del suministro municipal de agua de la ciudad. La ola resultante de manifestaciones y violencia policial se describió como una revuelta pública contra los precios del agua, pero tuvo un significado que va mucho más allá de Bolivia, prefigurando lo que ahora se considera uno de los lugares de batalla esenciales para el mercado mundial y la resistencia al avance del capital extractivo en el siglo XXI.

No obstante, la guerra del agua en Cochabamba y en otros lugares no resolvió el problema en lo que respecta a la última frontera del extractivismo, la pugna por la privatización del acceso al agua sigue siendo una cuestión

${ }^{19}$ Vandana Shiva, Water wars: privatization, polution and profit, New York, South End Press, 2002; Maude Barlow y Tony Clarke, Blue gold: the fight to stop the corporate theft of the world's water, New York, The New Press, 2005.
«Protectores de agua» indígenas y otros se oponen a la amenaza del capital extractivo sobre el agua en proyectos de infraestructura, como el gasoducto de Dakota en Estados Unidos.

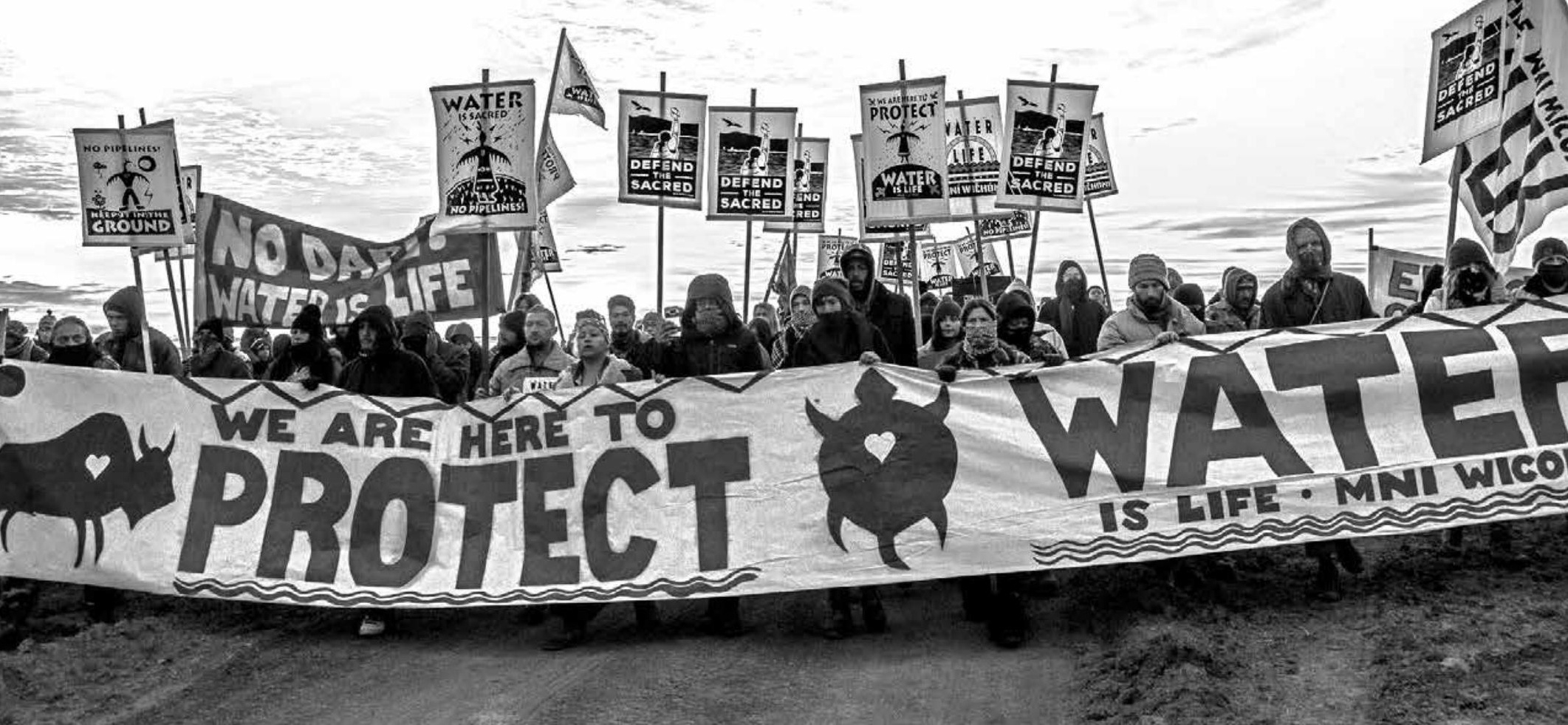


crucial para el capital extractivo y las comunidades de todo el mundo sobre el acceso abierto y libre a lo que no es sólo un recurso productivo fundamental sino una fuente de vida, un derecho humano vital.

La dinámica de esa lucha, la impugnación de los derechos de agua y los esfuerzos para fortalecer el control local de este recurso pueden rastrearse no sólo en los países andinos ${ }^{20}$ sino también en las fronteras mexicana y canadiense con Estados Unidos, donde la demanda de agua y el proceso de captación de agua se encuentran muy avanzados. ${ }^{21}$ Canadá, con 20 por ciento del agua dulce del mundo, es un sitio de interés continuo para el capital global y la resistencia; las exportaciones de agua a granel fueron excluidas del Tratado de Libre Comercio de América del Norte (TLCAN) de 1994, pero la propuesta de renegociación o incluso el posible desmantelamiento del Tratado propuesto por la administración de Donald Trump han creado el escenario para peleas renovadas por la mercantilización del agua. Al interior de Estados Unidos y Canadá, el surgimiento de los «protectores de agua» indígenas y otros que se oponen a la amenaza del capital extractivo en proyectos de infraestructura (como el gasoducto de Dakota en Estados Unidos) y las nuevas tecnologías como el fracking (fractura hidráulica), ilustran la internacionalización de la lucha por el agua. ${ }^{22}$

\section{Discusión interamericana}

Mientras que el extractivismo y las luchas que se derivan de él son comunes en diversos países latinoamericanos, de igual manera hay enredos, conexiones y paralelismos interamericanos, lo cual se puede apreciar al incluir a Canadá en la discusión. En primer lugar, gran

\footnotetext{
${ }^{20}$ Rutgerd Boelens, «Water fights arenas in the Andes», Water Alternatives, vol. 1, núm. 2, 2008, pp. 48-65.

${ }^{21}$ Maude Barlow, Blue gold: the global water crisis and the commodification of the world's water supply, San Francisco, International Forum on Globalization, 2009.

${ }^{22}$ Maude Barlow y Tony Clarke, op. cit.
}

parte del aumento de la IED en América Latina, dirigida cada vez más al sector de los recursos (cuadro 1), proviene de Canadá. Las cifras oficiales muestran que el stock de IED de Canadá en América Latina ascendió a 2 mil 600 millones de dólares canadienses en 1990, pero aumentó en más de 2 mil por ciento a 59 mil 400 millones de dólares canadienses en 2013. ${ }^{23}$ Esto fue cuatro veces más rápido que la tasa de crecimiento de la IED de Estados Unidos, lo que convirtió a Canadá en la segunda mayor fuente externa de IED en la región (después de Estados Unidos) entre 2007 y 2012. ${ }^{24}$ Además, la expansión del capital canadiense en el sector extractivo de América Latina fue fuertemente alentada y facilitada por el Estado canadiense. El nexo entre el Estado y el capital en dicho proceso ha sido tal que Canadá desempeñó el papel de lo que Gordon y Webber denominan una potencia imperialista secundaria. ${ }^{25}$

Si bien estos flujos demuestran los enredos capitalistas interamericanos, el proceso de extractivismo en Canadá constata muchas de las mismas características de la experiencia latinoamericana. El auge de los commodities de 2000-2014, impulsado por la demanda china, dio un enorme estímulo al extractivismo en Canadá, especialmente en el petróleo, el gas y los minerales (incluidos los metales preciosos, el molibdeno utilizado en la fabricación de acero, carbón y potasa). En ese momento el gobierno conservador alentó esta expansión creyendo que convertiría a Canadá en una «superpotencia energética».

Aunque la teoría de la dependencia en América Latina había cuestionado la viabilidad a largo plazo del extractivismo como estrategia de desarrollo y resaltaba la necesidad de industrialización, Canadá tenía su propia historia

\footnotetext{
${ }^{23}$ Todd Gordon y Douglas Webber, Blood of extraction: canadian imperialism in Latin America, Halifax, Fernwood Books, 2016, p. 15.

${ }^{24}$ Ibid., p. 16.

${ }^{25}$ Idem.
} 
referente a un debate similar. El enfoque de las materias primas (staples approach), descrito por Watkins como «la contribución más distintiva de Canadá a la economía política», ${ }^{26}$ analiza los impactos de las fuerzas globales en la exportación de recursos naturales de «nuevos países», como Canadá, caracterizado por bajos coeficientes entre la mano de obra y la tierra. Generado por Innis, el enfoque de las materias primas argumenta que la dependencia de las exportaciones de recursos naturales lleva a las economías de base a someterse a mayores volatilidades en los precios y la producción, a la falta de control sobre sus propios recursos económicos y el destino, las hacen dependientes de la entrada de capital extranjero y moldean sus culturas políticas. Los datos sobre la IED canadiense presentados anteriormente sugieren que el capital canadiense no es tan débil y subdesarrollado como podría implicar el enfoque de los productos básicos, pero las limitaciones de la estrategia extractivista siguen siendo trascendentales.

Para los seguidores de Innis, el extractivismo era visto como una limitante del desarro-

${ }^{26} \mathrm{Mel}$ Watkins, «A staple theory of economic growth», en Hugh Murray Grant y David Wolfe (eds.), Staples and beyond: selected writings of Mel Watkins, Montreal, McGi11-Queen's University Press, 2006, p. 5. llo, imponiendo obstáculos en el camino del desarrollo económico independiente e impidiendo que Canadá pasara a una economía capitalista madura; los países podrían quedar atrapados en una «trampa de las materias primas» o en la «camisa de fuerza del capitalismo blando», como lo llama Drache..$^{27}$ En efecto: el desarrollo económico era posible, sólo que tenía ciertas características limitantes. Igual que en el caso latinoamericano, se consideraba que producía economías de enclave, estructuralmente ligadas al resto de la economía e incapaces de generar una industrialización generalizada. Canadá había tratado de desarrollar su propio sector industrial detrás de los muros arancelarios, pero con la firma del Tratado de Libre Comercio entre Canadá y Estados Unidos en 1989 y el TLCAN en 1994, Canadá siguió el mismo camino neoliberal que los países latinoamericanos. El auge de las materias primas propició un valor elevado para el dólar canadiense, lo que impulsó la pérdida de empleos en el sector manufacturero y la mayor dependencia de las exportaciones de productos básicos.

${ }^{27}$ Daniel Drache, «Harold Innis and canadian capitalist Development», en Gordon Laxer (ed.), Perspectives on canadian economic development: class, staples gender and elites, Don Mills, Oxford University Press, 1991, p. 24.
Oleoducto,

al norte de Canadá.




Similar que en América Latina esto ha dado lugar a múltiples conflictos. Tres grandes líneas de desafío al modelo extractivista pueden ser identificadas e ilustradas con ejemplos del norte de Columbia Británica, región rica en recursos en la costa oeste de Canadá y que experimentó la atracción de las exportaciones de productos básicos a China de una manera particularmente intensa. El primer conjunto de desafíos surgió de las preocupaciones articuladas por el enfoque de las materias primas de que los proyectos extractivistas proporcionan sólo vínculos económicos limitados. Como ejemplo de esto, considérese la campaña llevada a cabo por una ONG local, Douglas Channel Watch, en Kitimat. ${ }^{28}$ Éste fue el término propuesto para el oleoducto Enbridge Northern Gateway, que transportaría petróleo de las arenas bituminosas de Alberta a Kitimat para su transporte a Asia. Sin embargo, en un plebiscito celebrado en abril de 2014, el municipio, de 9 mil personas, votó en contra de la propuesta de oleoducto, a pesar de que había sido aprobado por el Comité Federal de Revisión Conjunta (JRP, por sus siglas en inglés).

Tres de los cinco principales argumentos utilizados por la ONG apelaron directamente a la falta de vínculos con el resto de la economía y los limitados beneficios de empleo para los trabajadores locales. Tales argumentos se apoyaron en la conciencia pública de los límites del desarrollo de los productos básicos -implícitamente una referencia a la célebre caracterización de Innis de Canadá como compuesta de «cortadores de madera y acarreadores de agua» y un importante punto de referencia y narrativa en las comunidades de recursos. El enfoque en los impactos laborales limitados tiene paralelos en toda América, ya que el carácter de enclave del desarrollo extractivo ha sido reconocido por mucho tiempo. En adición, en toda América es una crí-

${ }^{28}$ Para una discusión amplia véase Paul Bowles \& Fiona MacPhail, «The Town That Said <No> to the Enbridge Northern Gateway Pipeline: The 2014 Kitimat Plebsicite», The Extractive Industries and Society, vol. 4, núm. 1, 2017, pp. 15-23. tica de la manera en que el trabajo se incorpora en el sector extractivo donde se encuentra; aunque a menudo relativamente bien pagado, ha sido el sitio de pugnas laborales prolongadas, y de confrontaciones entre la fuerza de trabajo por razones de género y racialidad. Si bien los trabajadores varones han dominado el empleo directo, la discriminación por género y etnia, la prostitución y el aumento de la violencia doméstica y sexual son comunes en los sitios extractivos.

En América Latina han surgido nuevas formas de protesta y oposición pública al extractivismo, una de ellas se refiere a las demandas de «justicia procesal». A los ojos de los opositores al extractivismo, esto ha sido violado por las formas en que los referendos y las consultas han sido ignorados en diversos países latinoamericanos. En Canadá, es posible hallar ejemplos como el Carrier Sekani Tribal Council (CSTC), que decidió boicotear las audiencias de la JRP sobre la propuesta del oleoducto Enbridge Northern Gateway debido a la falta de «paridad de participación»; no sentían que tenían los recursos, humanos o financieros, para competir con el proponente, la compañía de tuberías más grande del mundo. Debido a que no podían competir en igualdad de condiciones, creían que participar en el proceso de la JRP le habría proporcionado una apariencia de legitimidad que no merecía. El CSTC optó por obstruir las audiencias y unirse a otros en la continuación de acciones legales.

Un tercer tipo de oposición al extractivismo se cimenta en la preocupación y reconocimiento del medio ambiente. El hecho de que los proyectos de recursos naturales causen incertidumbre sobre los impactos ambientales lo constata. El reconocimiento se centra en la idea de que los valores y estilos de vida de todos los residentes son apreciados y validados, en concreto el de los grupos marginados, incluidos los pueblos indígenas. También puede ir más allá al reconocer que los medios de subsistencia no capitalistas alternativos pueden verse amenazados por los proyectos sobre los recursos. Esto puede 
incluir las formas de acumulación por desposesión y la mercantilización de la naturaleza y el trabajo. Como ejemplo, es posible considerar la oposición a la propuesta de Petronas (ahora retirada) en el norte de la Columbia Británica para una terminal de LNG en la isla de Lelu en la costa noroeste, una oposición encabezada por las First Nations (en este caso los Lax Kw'alaams Hereditary Chiefs y miembros de la comunidad), pero con el apoyo de una amplia gama de otras organizaciones e individuos que comprenden tanto las comunidades indígenas como las comunidades de colonos. La desazón es que la terminal triturará las áreas de desove del salmón, lo que ha movilizado a muchos que confían en el salmón salvaje para fines recreativos y de subsistencia. Incluye varios en el noroeste, indígenas y no indígenas, que dependen del salmón para subsistencia y para compartir en formas no capitalistas. Dichas alternativas de organización social, por lo general basadas en las economías locales, son amenazadas por proyectos de recursos industriales y proponentes que no entienden ni explican su existencia, hecho que genera oposición.

\section{Conclusiones}

El extractivismo - una fase de desarrollo capitalista basada en la explotación de las materias primas más que del trabajo - regresó a las Américas como estrategia de desarrollo económico en la década de 1980. En América Latina y Canadá, fue impulsado por una agenda política neoliberal, situación que condujo a una reprimarización de la economía. El giro posneoliberal en algunos de los países latinoamericanos dejó el extractivismo en su lugar, pero lo reenvasaron en formas de desarrollo «inclusivo» o «sustentable». La dependencia de la IED para apoyar el extractivismo se logró en parte mediante el aumento de la IED procedente de Canadá y Estados Unidos. Así, la nueva dependencia en el continente meridional se reflejó por el renovado imperialismo del continente septentrional.

En ambos continentes y en algunos temas comunes el extractivismo ha generado oposición. Éstos incluyen la naturaleza problemática del extractivismo como modelo de desarrollo generador de empleo, las consecuencias ambientales adversas que convierten a algunas áreas en «ZOnas de sacrificio» y la destrucción de modos de vida alternativos. Lo anterior es especialmente crítico para los pueblos indígenas y sus culturas que están amenazadas por expansiones terrestres de procesos extractivos y que por consiguiente se encuentran a menudo como los líderes de la resistencia al extractivismo. Las comunidades indígenas se han unido en todos los continentes y han descubierto una causa común en su apoyo al reconocimiento y adhesión a los Derechos de los Pueblos Indígenas de las Naciones Unidas, en particular al derecho al consentimiento libre, previo e informado.

Los movimientos sociales y las ONG también han formado alianzas para el intercambio de información y la promoción en todos los continentes, como lo demuestran organizaciones canadienses como Mining Watch. El fin del auge mundial de las materias primas, la resistencia creciente y organizada, junto con la creciente severidad del cambio climático mundial, pueden apuntar a una relajación de la dependencia del extractivismo por parte de los Estados, pero es poco probable que sea una solución a largo plazo, ya que la lógica del extractivismo capitalista es seguir explotando los recursos hasta que desaparezcan. 